\title{
Influence of lean and fat mass on bone mineral density and on urinary stone risk factors in healthy women
}

Antonio Nouvenne ${ }^{1 *}$, Andrea Ticinesi ${ }^{1}$, Angela Guerra ${ }^{1}$, Giuseppina Folesani ${ }^{1}$, Franca Allegri ${ }^{1}$, Silvana Pinelli ${ }^{1}$, Paolo Baroni ${ }^{2}$, Mario Pedrazzoni ${ }^{1}$, Giuseppe Lippi ${ }^{3}$, Annalisa Terranegra ${ }^{4}$, Elena Dogliotti ${ }^{4}$, Laura Soldati ${ }^{4}$, Loris Borghi ${ }^{1}$ and Tiziana Meschi ${ }^{1}$

\begin{abstract}
Background: The role of body composition (lean mass and fat mass) on urine chemistries and bone quality is still debated. Our aim was therefore to determine the effect of lean mass and fat mass on urine composition and bone mineral density (BMD) in a cohort of healthy females.

Materials and methods: 78 female volunteers (mean age $46 \pm 6$ years) were enrolled at the Stone Clinic of Parma University Hospital and subdued to 24-hour urine collection for lithogenic risk profile, DEXA, and 3-day dietary diary. We defined two mathematical indexes derived from body composition measurement (index of lean mass-ILM, and index of fat mass-IFM) and the cohort was split using the median value of each index, obtaining groups differing only for lean or fat mass. We then analyzed differences in urine composition, dietary intakes and BMD.

Results: The women with high values of ILM had significantly higher excretion of creatinine (991 \pm 194 vs $1138 \pm$ $191 \mathrm{mg} /$ day, $\mathrm{p}=0.001$ ), potassium (47 \pm 13 vs $60 \pm 18 \mathrm{mEq} /$ day, $p<0.001$ ), phosphorus (520 \pm 174 vs $665 \pm 186 \mathrm{mg} /$ day, $p<0.001)$, magnesium ( $66 \pm 20$ vs $85 \pm 26 \mathrm{mg} /$ day, $p<0.001)$, citrate $(620 \pm 178$ vs $807 \pm 323 \mathrm{mg} /$ day, $p=0.002$ ) and oxalate ( $21 \pm 7$ vs $27 \pm 11 \mathrm{mg} /$ day, $p=0.015$ ) and a significantly better BMD values in limbs than other women with low values of ILM. The women with high values of IFM had similar urine composition to other women with low values of IFM, but significantly better BMD in axial sites. No differences in dietary habits were found in both analyses.
\end{abstract}

Conclusions: Lean mass seems to significantly influence urine composition both in terms of lithogenesis promoters and inhibitors, while fat mass does not. Lean mass influences bone quality only in limb skeleton, while fat mass influences bone quality only in axial sites.

Keywords: Body composition, Lean mass, Fat mass, Bone mineral density, Urinary lithogenic risk factors

\section{Introduction}

The role of body weight, body mass index and body composition in the evaluation of lithogenic risk is still controversial. Even if many studies show an increase in the risk of developing nephrolithiasis with higher levels of BMI, the exact contribution of lean mass and fat mass in determining this risk is still unclear.

There are some large epidemiologic studies recording a rise in the risk of kidney stones as body weight, BMI

\footnotetext{
* Correspondence: antonio.nouvenne@alice.it

1 Department of Clinical and Experimental Medicine, University of Parma, Via A. Gramsci 14, Parma 43126, Italy

Full list of author information is available at the end of the article
}

and abdominal circumference increase [1,2]. The rise in the risk is however associated to a change in the type of nephrolithiasis, with the prevalence of calcium stones decreasing and the prevalence of uric acid stones increasing [3-5]. A rise in lean body mass has been linked to an increase in the incidence of nephrolithiasis only in male [6]. Moreover, a loss of weight is not associated to a decline in the risk [2].

On the other hand, if we consider urinary factors of lithogenic risk, an inverse correlation between $\mathrm{pH}$ and BMI and between $\mathrm{pH}$ and fat mass has been reported [7]. Moreover, the excretion of oxalate has been linked to body weight, body surface area and to lean mass [8].

\section{Biomed Central}


The excretion of oxalate, uric acid, sodium, phosphate and calcium rises when BMI increases [9-11]; however, the calcium excretion loses significance after correction for sodium and phosphate [9].

Some recent studies have also shown a positive relation between urinary lithogenic risk factors, overweight and obesity [12-14]. Nevertheless, relative supersaturations are not altered since even inhibitor excretion and water intake increase with the body weight and/or BMI percentiles growth. A common limit of many of these studies is the lack of a precise evaluation of dietary habits, particularly in protein intake $[15,16]$.

Even the relation between body composition and bone mineral density is debated. It has been demonstrated that an increase in body weight improves bone mineral density, but the specific role of lean mass and fat mass remains uncertain such as different effects in men and women [17]. There is a positive relation, proven in many studies, between fat mass and vertebral bone mineral density, while lean mass seems to be related to a higher bone mineral density only in some areas and is highly influenced by age and physical exercise [18-20]. On the other hand a link between urine chemistries, body composition and bone mineral density has been described $[21,22]$.

In this paper, basing on a cohort of healthy women, we identified two new mathematical indexes pointing out the role of lean body mass and fat body mass separately, trying to eliminate possible confounding factors (e.g. height) present in already validated indices such as the Fat-Free Mass Index and Fat Mass Index [23]. Therefore we verified: 1) whether the urinary excretion of lithogenic risk factors is influenced by the whole body weight or by its composition in lean mass and fat mass; 2) how the bone mineral density is related to body composition; 3) which are the body areas where lean mass or fat mass most influence bone mineral density.

\section{Materials and methods Participants}

We studied 78 healthy female volunteers at the Stone Clinic of the Clinical and Experimental Medicine Department, Parma University Hospital, Italy. Approvation by Ethical Committee of Parma Province was obtained as well as written informed consent from the patient for the publication of this report and any accompanying images. The study was carried out in compliance with the Helsinki Declaration.

All women carried out: 1) 24-hour urine collection for the laboratory determination of urinary lithogenic risk factors; 2) bone mineral density and body composition measurement through Dual-Energy X-Ray Absorptiometry with a fan-beam Hologic QDR 4500A densitometer (Hologic, Bedford, Mass., USA); 3) 3-day dietary diary in non-consecutive days with one corresponding to the day of the urinary collection, subsequently analyzed by a dietitian and interpreted with a specific software (Dietosystem, DS Medica, Milano, Italy).

\section{Densitometry}

Body Composition was measured by DEXA with a fan beam densitometer (Hologic QDR 4500 A) and dedicated software (rel. 8.2). In the DEXA measurement, a trained physician performed the measurements on the women. DEXA measurements were performed following standard procedures, according to the manufacturer's guidelines, while the participant was lying in a supine position. The trunk was considered as the region delimited by a horizontal line passing under the chin, two vertical lines passing through the medial margin of the head of the homerus, excluding all of the upper limbs, and two oblique lines at the groin cutting midway through the neck of the femur and crossing below the pubis. Intra-site repeatability was a mean of $2-3$ \& for FM. The coefficients of variation for the method were assessed by repeated measurements.

\section{Definition of mathematical indexes for body lean mass and body fat mass \\ Index of lean mass (ILM)}

We defined an index in order to obtain two groups of women not different for body weight and BMI but only for lean mass. Body weight (BW), lean mass (LM) and fat mass (FM) are not independent variables because we can assume that total body weight is the sum of lean mass and fat mass.

ILM has been conceived for not being influenced by body weight, i.e.:

Since

$$
\mathrm{BW}=\mathrm{LM}+\mathrm{FM}
$$

Then

$$
\mathrm{ILM}=\mathrm{BW} \times(\mathrm{LM}-\mathrm{FM})
$$

That we can also write as

$$
\mathrm{ILM}=(\mathrm{LM}+\mathrm{FM}) \times(\mathrm{LM}-\mathrm{FM})
$$

And therefore

$$
\mathrm{ILM}=\mathrm{LM}^{2}-\mathrm{FM}^{2}
$$

Since every woman studied has a lean body mass higher than the fat body mass, elevating their values to the power of two we obtain the higher difference the heavier the lean mass is.

Therefore we calculated the value of ILM for every woman involved in the study, we found its median and we split our population in two groups (group A with ILM values lower than the median and group B with 
ILM values higher than the median). These two groups were characterized by a strong difference in lean body mass $(\mathrm{p}<0.0001)$, but were not significantly different for fat mass, body weight and BMI.

\section{Index of fat mass (IFM)}

We defined an index in order to obtain two groups not differing for lean mass:

$$
\begin{aligned}
\text { IFM } & =\mathrm{BW} /(\mathrm{LM}-\mathrm{FM}) \text { and therefore IFM } \\
& =(\mathrm{LM}+\mathrm{FM}) /(\mathrm{LM}-\mathrm{FM})
\end{aligned}
$$

Since an increase in body weight is generally associated to an increase both in lean mass and in fat mass, but the extent of the increase is higher for fat mass, the higher is body weight, the higher is the numerator and the lower is the difference between lean mass and fat mass, and, subsequently, the higher is the value of IFM.

Thus, we calculated the value of IFM for every subject studied, we found its median and subsequently split our population into two groups (group $\mathrm{C}$ with IFM values lower than the median and group D with IFM values higher than the median). These two groups are characterized by a strong difference in fat mass, body weight and BMI $(\mathrm{p}<0.0001)$, while there are no significant differences for the lean mass composition.

\section{Statistical analysis}

Data distribution was assessed using Shapiro-Wilk's test. Data were reported as media and standard deviation (SD). Data with deviations from normality were shown as median and range. Differences between the two groups in all tables were calculated using independent Student's t-test or Mann-Whitney's U-test. A p value lower than 0.05 was considered significant for t-test or U-test. Holm's test [24] was applied to adjust p values for multiple comparisons. Holm's statistical procedures rejected an hypothesis only if its p-value was less than their corresponding critical values. Holm's test was supported also by a discriminant analysis reported in Tables 1, 2 and 3 Pearson's correlation coefficient (r) was reported for all parameters quantified. The data were statistically analysed using SPSS 20.0 (SPSS inc. Chicago, IL, USA).

\section{Results}

The average age of the 78 women studied was $46 \pm$ 6 years (range 31-59). 24\% of them (19 women) had been menopausal since at least one year.

\section{ILM and IFM validation}

Indexes validation was carrying out as follows. Weight, total lean mass and total fat mass are parameters strongly correlated to each other (weight $v s$ total lean
Table 1 Discriminant function analysis for body composition of healthy women split into two groups based on the Index of Lean Mass (ILM)

\begin{tabular}{lc}
\hline Parameter & $\begin{array}{c}\text { Standardized canonical } \\
\text { discriminant function coefficient }\left(^{*}\right)\end{array}$ \\
\hline Index of Lean Mass (ILM) & 0.81 \\
Total lean mass, Kg & 0.44 \\
Height, cm & 0.31 \\
BMD upper limb, g/ $\mathrm{cm}^{2}$ & 0.25 \\
\hline
\end{tabular}

(*) Parameters with coefficient $>0.25$. Lambda of Wilks $(p<0.001)$. BMD: Bone Mineral Density.

mass, $\mathrm{r}=0.839$ and $\mathrm{p}<0.0001$; weight vs total fat mass, $\mathrm{r}=0.909$ and $\mathrm{p}<0.0001$; total fat mass $v s$ total lean mass, $\mathrm{r}=0.538$ and $\mathrm{p}<0.0001$, where $\mathrm{r}$ is a Pearson's correlation coefficient). Multiple regression can be performed using least-squares method: total lean mass is dependent variable and weight is predictor, ILM (Index of Lean Mass) is reported in the model as covariate variable. This multiple regression is highly significant with $\mathrm{p}<0.0001$, $R^{2}=0.989$ and $R=0.995$. A simple linear regression with only weight as independent variable resulting $R^{2}=0.70$ and $R=0.84$. So ILM is very important in the explanation of the model. Total lean mass adjusted for weight correlates significantly with different parameters of urinary excretion and density bones. These Pearson's correlations provide results equal to values obtained from the correlations of ILM with same parameters. ILM is independent from the weight and also from BMI. For example two subjects may have the same weight's and height's values (same $\mathrm{BMI}$ ), but lean total mass completely different. ILM is a parameter more specific for total lean mass. Now it is clear that subjects with high lean total mass not have necessary low total fat mass. The second index IFM correlates highly significant with total fat mass, $r=0.689$ and $\mathrm{p}<0.0001$ and it is not correlated with total lean mass. These correlations are confirmed by Discriminant Function

\section{Table 2 Discriminant function analysis for urinary lithogenic risk factors on a 24-hour urine collection in healthy women split into two groups based on the Index of Lean Mass (ILM)}

\begin{tabular}{lc}
\hline Parameter & $\begin{array}{c}\text { Standardized canonical } \\
\text { discriminant function coefficient }\left(^{*}\right)\end{array}$ \\
\hline Potassium, mEq/24 h & 0.52 \\
Magnesium, mg/24 h & 0.51 \\
Phosphorus, mg/24 h & 0.50 \\
Creatinine, mg/24 h & 0.48 \\
Citrate, mg/24 h & 0.44 \\
Oxalate, mg/24 h & 0.35 \\
Sodium, mEq/24 h & 0.26 \\
\hline
\end{tabular}

(*) Parameters with coefficient $>0.25$. Lambda of Wilks $(p=0.003)$. 
Table 3 Discriminant function analysis for body composition in healthy women split into two groups based on the Index of Fat Mass (IFM)

\begin{tabular}{lc}
\hline Parameter & $\begin{array}{c}\text { Standardized canonical } \\
\text { discriminant function coefficient }\left(^{*}\right)\end{array}$ \\
\hline Total fat mass, $\mathrm{Kg}$ & 0.67 \\
$\mathrm{BMl}, \mathrm{Kg} / \mathrm{m}^{2}$ & 0.51 \\
Weight, $\mathrm{Kg}$ & 0.41 \\
Total lower limb mass, $\mathrm{Kg}$ & 0.41 \\
Total trunk mass, Kg & 0.37 \\
Index of Fat Mass (IFM) & 0.26 \\
\hline
\end{tabular}

(*) Parameters with coefficient $>0.25$. Lambda of Wilks $(p<0.001)$. BMI: Body Mass Index.
Analysis by standardized canonical discriminant function coefficients reported in Tables 1, 2 and 3.

Table 4 shows the values of body composition and Table 5 shows the urinary lithogenic risk factors after partition of the women according to the median (1296) of the Index of Lean Mass. Groups A and B did not differ in body weight and BMI, but women in group B showed height and lean mass significantly higher $(159 \pm 6$ vs $163 \pm 5 \mathrm{~cm}$ and $40 \pm 4$ vs $45 \pm 5 \mathrm{~kg}, \mathrm{p}<0.0001)$. Moreover, the group with high ILM showed a bone mineral density significantly higher in both upper and lower limbs and in ribs (Table 4).

The subjects of group B (with high lean mass) also showed urinary excretion of creatinine, potassium, phosphorus, magnesium, citrate and oxalate significantly higher than the ones of group A (Table 5).

Table 4 Body composition of healthy women split into two groups based on the Index of Lean Mass (ILM)

\begin{tabular}{|c|c|c|c|c|}
\hline & $\begin{array}{c}\text { Group } A \\
\text { Low lean mass } \\
\text { ILM }<1296 \\
\text { N. } 39\end{array}$ & $\begin{array}{c}\text { Group B } \\
\text { High lean mass } \\
\text { ILM > } 1296 \\
\text { N. } 39\end{array}$ & $p(*)$ & $\begin{array}{c}\mathrm{p} \text { critical values } \\
(0.0029<\mathrm{p}<0.0025)\end{array}$ \\
\hline ILM & $1035 \pm 205$ & $1625 \pm 313$ & $<0.0001$ & \#\#\# \\
\hline Age, years & $46 \pm 6$ & $46 \pm 6$ & 0.956 & \\
\hline Menopausal, n., \% ( $\left(^{\circ}\right)$ & $11(28)$ & $8(21)$ & $0.590^{* *}$ & \\
\hline Years from menopause & $1.4 \pm 3$ & $0.9 \pm 2$ & 0.416 & \\
\hline Weight, Kg & $65 \pm 10$ & $68 \pm 11$ & 0.268 & \\
\hline Height, cm & $159 \pm 6$ & $163 \pm 5$ & $<0.0001$ & \#\#\# \\
\hline $\mathrm{BMI}, \mathrm{Kg} / \mathrm{m}^{2}$ & $26 \pm 4$ & $25 \pm 4$ & 0.612 & \\
\hline Total trunk mass, $\mathrm{Kg}$ & $31 \pm 5$ & $32 \pm 6$ & 0.289 & \\
\hline Total lower limb mass, $\mathrm{Kg}$ & $22 \pm 4$ & $23 \pm 4$ & 0.460 & \\
\hline Total lean mass, Kg & $40 \pm 4$ & $45 \pm 5$ & $<0.0001$ & \#\#\# \\
\hline Total fat mass, $\mathrm{Kg}$ & $23 \pm 6$ & $21 \pm 7$ & 0.07 & \\
\hline BMD upper limbs, $\mathrm{g} / \mathrm{cm}^{2}$ & $0.72 \pm 0.04$ & $0.76 \pm 0.08$ & 0.003 & \#\#\# \\
\hline BMD ribs, $\mathrm{g} / \mathrm{cm}^{2}$ & $0.64 \pm 0.08$ & $0.68 \pm 0.07$ & 0.035 & \\
\hline BMD lower limbs, $\mathrm{g} / \mathrm{cm}^{2}$ & $1.10 \pm 0.07$ & $1.15 \pm 0.1$ & 0.026 & \\
\hline BMD pelvis, $\mathrm{g} / \mathrm{cm}^{2}$ & $1.20 \pm 0.15$ & $1.24 \pm 0.18$ & 0.307 & \\
\hline BMD lumbar vertebrae, $\mathrm{g} / \mathrm{cm}^{2}$ & $1 \pm 0.13$ & $1.04 \pm 0.15$ & 0.217 & \\
\hline BMD femur, $\mathrm{g} / \mathrm{cm}^{2}$ & $0.91 \pm 0.12$ & $0.95 \pm 0.11$ & 0.232 & \\
\hline T-score lumbar vertebrae $(+)$ & $-0.17(-2.50-2.31)$ & $-0.45(-2.54-2.87)$ & $0.442^{* * *}$ & \\
\hline Z-score lumbar vertebrae (+) & $0.41(-1.92-2.73)$ & $0.34(-1.49-3.21)$ & $0.407^{* * *}$ & \\
\hline T-score femur $(+)$ & $-0.16(-1.92-2.07)$ & $-0.09(-1,50-1.52)$ & $0.165^{* * *}$ & \\
\hline Z-score femur (+) & $0.27(-1.52-2.43)$ & $0.37(-1.27-1.93)$ & $0.225^{* * *}$ & \\
\hline
\end{tabular}

Data were reported as mean \pm standard deviation (SD), unless otherwise specified.

'Data were reported as number of subjects (frequency).

+Data were reported as median and range.

* $p$ value was calculated with nondependent Student's $t$ test, unless otherwise specified.

$*{ }^{2} x^{2}$ test was applied to evaluate $p$ value.

***Mann-Whithey's u-test was applied to evaluate $p$ value.

\#\#\#Significant differences with $\mathrm{p}$ adjusted by Holm's test.

BMD: Bone Mineral Density. 
Table 5 Urinary lithogenic risk factors on a 24-hour urine collection in healthy women split into two groups based on the Index of Lean Mass (ILM)

\begin{tabular}{|c|c|c|c|c|}
\hline & $\begin{array}{c}\text { Group A } \\
\text { Low lean mass } \\
\text { ILM }<1296 \\
\text { N. } 39 \\
\end{array}$ & $\begin{array}{c}\text { Group B } \\
\text { High lean mass } \\
\text { ILM }>1296 \\
\text { N. } 39 \\
\end{array}$ & $P(*)$ & $\begin{array}{c}p \text { critical values } \\
(0.0038<p<0.003)\end{array}$ \\
\hline Volume, ml & $1603 \pm 698$ & $1640 \pm 835$ & 0.832 & \\
\hline Creatinine, mg/24 h & $991 \pm 194$ & $1138 \pm 191$ & 0.001 & \#\#\# \\
\hline Urea, mg/24 h & $22 \pm 6$ & $23 \pm 6$ & 0.486 & \\
\hline Sodium, mEq/24 h & $124 \pm 49$ & $143 \pm 45$ & 0.072 & \\
\hline Potassium, mEq/24 h & $47 \pm 13$ & $60 \pm 18$ & $<0.001$ & $\# \#$ \\
\hline Calcium, mg/24 h & $156 \pm 62$ & $188 \pm 91$ & 0.076 & \\
\hline Phosphorus, mg/24 h & $520 \pm 174$ & $665 \pm 186$ & $<0.001$ & \#\#\# \\
\hline Magnesium, mg/24 h & $66 \pm 20$ & $85 \pm 26$ & $<0.001$ & $\# \#$ \\
\hline Chloride, mEq/24 h & $131 \pm 50$ & $151 \pm 49$ & 0.074 & \\
\hline Uric acid, mg/24 h & $456 \pm 136$ & $508 \pm 116$ & 0.077 & \\
\hline Citrate, mg/24 h & $620 \pm 178$ & $807 \pm 323$ & 0.002 & \#\#\# \\
\hline Oxalate, mg/24 h & $21 \pm 7$ & $27 \pm 11$ & 0.015 & \\
\hline Sulfate, $\mathrm{mmol} / 24 \mathrm{~h}$ & $16 \pm 4$ & $18 \pm 5$ & 0.085 & \\
\hline Ammonium, mmol/24 h & $27 \pm 11$ & $30 \pm 9$ & 0.275 & \\
\hline $\mathrm{pH} 24 \mathrm{~h}$ & $5.95 \pm 0.51$ & $5.96 \pm 0.45$ & 0.961 & \\
\hline
\end{tabular}

Data were reported as mean \pm standard deviation (SD).

*p value was calculated with independent Student's t-test.

\#\#\#Significant differences with $\mathrm{p}$ adjusted by Holm's test.

The analysis of three-day dietary diaries did not show differences in the intake of water. Potential Renal Acid Load (PRAL calculated) [25], proteins, carbohydrates, lipids, sodium, potassium, calcium, phosphorus, and magnesium did not show differences between the two ILM groups (Table 6). The percentage of subjects that regularly performed physical exercise (according to WHO guidelines [26]) was not significantly different as well (Group A 31\% vs Group B 49\%, p = 0.105).

Table 7 shows the values of body composition and Table 8 the urinary lithogenic risk factors after subdivision of the women according to the median (3.28) of the Index of Fat Mass. The two groups did not differ in height, but the group with a higher IFM showed significantly greater values of BMI, total trunk mass, total leg mass and total body fat mass. The bone mineral density of the pelvis, lumbar vertebrae and femur, and the respective $\mathrm{T}$ and $\mathrm{Z}$ score, were significantly better in Group D, the one with high IFM (Table 7).

The urinary lithogenic risk factors (Table 8) showed no differences between Group C (subjects with low IFM) and Group D (subjects with high IFM); besides, even dietary intakes did not reveal significant differences (Table 9). The percentage of subjects regularly performing physical activity appeared instead significantly higher in women with a low Index of Fat Mass (Group C 54\% vs Group D 26\%, $\mathrm{p}=0.01)$.
Table 6 Dietary intake of healthy women split into two groups based on the Index of Lean Mass (ILM)

\begin{tabular}{lccc} 
& Group A & Group B & p (*) \\
& Low lean mass & High lean mass & \\
& ILM $<$ 1296 & ILM > 1296 & \\
\hline Water, ml $\mathbf{3 9}$ & N. 39 & \\
PRAL, mEq & $1470 \pm 560$ & $1470 \pm 670$ & 1.000 \\
Proteins, g/24 h & $12.75 \pm 17.45$ & $6.69 \pm 18.85$ & 0.145 \\
Carbohydrates, g/24 h & $258 \pm 89$ & $89 \pm 30$ & 0.215 \\
Lipids, mEq/24 h & $82 \pm 29$ & $272 \pm 92$ & 0.493 \\
Sodium, mEq/24 h & $80 \pm 44$ & $93 \pm 29$ & 0.101 \\
Potassium, mEq/24 h & $66 \pm 18$ & $95 \pm 61$ & 0.212 \\
Calcium, mg/24 h & $757 \pm 416$ & $73 \pm 23$ & 0.150 \\
Phosphorus, mg/24 h & $1150 \pm 418$ & $1105 \pm 350$ & 0.610 \\
Magnesium, mg/24 h & $261 \pm 97$ & $295 \pm 126$ & 0.181 \\
\hline Data were reported as mean & & &
\end{tabular}

Data were reported as mean \pm standard deviation (SD).

* $p$ value was calculated with independent Student's t-test.

PRAL: Potential Renal Acid Load. The Dietosystem software (DS Medica) calculates PRAL applying the original model described by Remer and Manz (ref). 
Table 7 Body composition in healthy women split into two groups based on the Index of Fat Mass (IFM)

\begin{tabular}{|c|c|c|c|c|}
\hline & $\begin{array}{c}\text { Group C } \\
\text { Low fat mass } \\
\text { IFM }<3.28 \\
\text { N. } 39\end{array}$ & $\begin{array}{c}\text { Group D } \\
\text { High fat mass } \\
\text { IFM }>3.28 \\
\text { N. } 39\end{array}$ & $p(*)$ & $\begin{array}{c}\mathrm{p} \text { critical value } \\
(0.0036<\mathrm{p}<0.0025)\end{array}$ \\
\hline IFM & $2.50 \pm 0.42$ & $5.14 \pm 4.03$ & $<0.0001$ & \#\#\# \\
\hline Age, years & $45 \pm 6$ & $47 \pm 6$ & 0.23 & \\
\hline Menopause, n., \% ( $\left.{ }^{\circ}\right)$ & $8(21)$ & $11(28)$ & $0.429^{* *}$ & \\
\hline Years from menopause & $0.8 \pm 3$ & $1.5 \pm 3$ & 0.336 & \\
\hline Weight, Kg & $60 \pm 7$ & $73 \pm 10$ & $<0.0001$ & \#\#\# \\
\hline Height, $\mathrm{cm}$ & $161 \pm 6$ & $161 \pm 6$ & 0.467 & \\
\hline $\mathrm{BMI}, \mathrm{Kg} / \mathrm{m}^{2}$ & $23 \pm 2$ & $28 \pm 3$ & $<0.0001$ & \#\#\# \\
\hline Total trunk mass, $\mathrm{Kg}$ & $28 \pm 4$ & $35 \pm 6$ & $<0.0001$ & \#\#\# \\
\hline Total lower limb mass, $\mathrm{Kg}$ & $21 \pm 3$ & $25 \pm 3$ & $<0.0001$ & \#\#\# \\
\hline Total lean mass, $\mathrm{Kg}$ & $41 \pm 5$ & $43 \pm 5$ & 0.064 & \\
\hline Total fat mass, $\mathrm{Kg}$ & $17 \pm 3$ & $27 \pm 5$ & $<0.0001$ & \#\#\# \\
\hline BMD upper limbs, $\mathrm{g} / \mathrm{cm}^{2}$ & $0.74 \pm 0.08$ & $0.73 \pm 0.06$ & 0.347 & \\
\hline BMD ribs, $\mathrm{g} / \mathrm{cm}^{2}$ & $0.66 \pm 0.08$ & $0.66 \pm 0.07$ & 0.886 & \\
\hline BMD lower limbs, $\mathrm{g} / \mathrm{cm}^{2}$ & $1.13 \pm 0.09$ & $1.13 \pm 0.09$ & 0.896 & \\
\hline BMD pelvis, $\mathrm{g} / \mathrm{cm}^{2}$ & $1.18 \pm 0.15$ & $1.27 \pm 0.17$ & 0.013 & \\
\hline BMD lumbar vertebrae, $\mathrm{g} / \mathrm{cm}^{2}$ & $0.98 \pm 0.13$ & $1.06 \pm 0.14$ & 0.018 & \\
\hline BMD femur, $\mathrm{g} / \mathrm{cm}^{2}$ & $0.90 \pm 0.10$ & $0.96 \pm 0.12$ & 0.025 & \\
\hline T-score lumbar vertebrae $(+)$ & $-0.55(-2.54-2.87)$ & $0.25(-2.50-2.68)$ & $0.013^{* * *}$ & \\
\hline Z-score lumbar vertebrae $(+)$ & $-0.13(-1.92-3.19)$ & $0.63(-1.46-3.21)$ & $0.004^{* * *}$ & \\
\hline T-score femur $(+)$ & $-0.52(-1.55-1.25)$ & $0.24(-1.92-2-07)$ & $0.034^{* * *}$ & \\
\hline Z-score femur $(+)$ & $-0.18(-1.27-1.93)$ & $0.61(-1.52-2.43)$ & $0.014^{* * *}$ & \\
\hline
\end{tabular}

Data were reported as mean \pm standard deviation (SD), unless otherwise specified.

${ }^{\circ}$ Data were reported as number of patients (frequency).

+ Data were reported as median and range.

*p value was calculated with independent Student's t-test, unless otherwise specified.

${ }^{* *} X^{2}$ test was applied to evaluate $p$ value.

***Mann-Whitney's u-test was applied to evaluate $p$-value.

\#\#\#Significant differences with $\mathrm{p}$ adjusted by Holm's test.

BMD: Bone Mineral Density.

Discriminant function analysis for body composition and urine chemistries regarding ILM and IFM are reported in Tables 1 and 2 for ILM and Table 3 for IFM.

\section{Discussion}

Our data demonstrate that the urine composition in our cohort of female healthy volunteers is significantly influenced by the body composition in lean mass. A high lean mass promotes a high excretion both of some lithogenesis promoters, such as phosphate and oxalate, and of some lithogenesis inhibitors, such as magnesium, potassium and citrate. A positive trend also seems to occur with other urinary analytes such as sodium, chloride, uric acid and sulphate, although at the limit of statistical significance, perhaps because of the relatively low number of subjects studied.

It seems plausible to argue that these findings were not due to differences in dietary intake, as demonstrated by a nutritional analysis performed through a 3-day dietary diary. We can therefore assume that lean mass plays an active role in determining urine composition, while fat mass seems to act as a metabolically inactive bystander.

This hypothesis partially conflicts with the current paradigm that considers nephrolithiasis as a systemic disorder strongly linked to metabolic syndrome. There are data showing that a high insulin resistance, possible expression of a high fat mass, leads to lower urinary $\mathrm{pH}$, to a high acid load and ammonium excretion [27]. This would expose subjects with a high fat mass to a higher risk of uric acid stones, although there are also data linking various features of the metabolic syndrome to calcium nephrolithiasis too [28]. These findings may explain the strong epidemiologic correlation between obesity and kidney stones [3-5]. 
Table 8 Urinary lithogenic risk factors on a 24-hour urine collection in healthy women, split into two groups based on the Index of Fat Mass (IFM)

\begin{tabular}{|c|c|c|c|}
\hline & $\begin{array}{c}\text { Group C } \\
\text { Low fat mass } \\
\text { IFM }<3.28 \\
\text { N. } 39\end{array}$ & $\begin{array}{c}\text { Group D } \\
\text { High fat mass } \\
\text { IFM }>3.28 \\
\text { N. } 39\end{array}$ & $p(*)$ \\
\hline Volume, ml & $1692 \pm 793$ & $1551 \pm 740$ & 0.418 \\
\hline Creatinine, mg/24 h & $1034 \pm 201$ & $1095 \pm 207$ & 0.188 \\
\hline Urea, mg/24 h & $22 \pm 6$ & $22 \pm 6$ & 0.807 \\
\hline Sodium, mEq/24 h & $130 \pm 45$ & $137 \pm 51$ & 0.501 \\
\hline Potassium, mEq/24 h & $55 \pm 18$ & $53 \pm 17$ & 0.677 \\
\hline Calcium, mg/24 h & $178 \pm 90$ & $167 \pm 67$ & 0.537 \\
\hline Phosphorus, mg/24 h & $574 \pm 196$ & $611 \pm 192$ & 0.402 \\
\hline Magnesium, mg/24 h & $80 \pm 28$ & $71 \pm 21$ & 0.138 \\
\hline Chloride, mEq/24 h & $138 \pm 48$ & $144 \pm 53$ & 0.622 \\
\hline Uric acid, mg/24 h & $469 \pm 120$ & $495 \pm 136$ & 0.363 \\
\hline Citrate, mg/24 h & $736 \pm 292$ & $691 \pm 261$ & 0.478 \\
\hline Oxalate, mg/24 h & $23 \pm 7$ & $26 \pm 12$ & 0.162 \\
\hline Sulfate, $\mathrm{mmol} / 24 \mathrm{~h}$ & $17 \pm 4$ & $17 \pm 5$ & 0.526 \\
\hline Ammonium, mmol/24 h & $28 \pm 9$ & $29 \pm 12$ & 0.881 \\
\hline $\mathrm{pH} 24 \mathrm{~h}$ & $6.00 \pm 0.43$ & $5.92 \pm 0.53$ & 0.451 \\
\hline
\end{tabular}

Data were reported as mean \pm standard deviation (SD).

*p value was calculated with independent Student's t-test.

On the other hand, there are also some reports indirectly suggesting that fat mass does not affect lithogenic risk until BMI rises to the range of morbid obesity. For example, Taylor et al. found that lithogenic risk does not rise for a body weight up to $67.7 \mathrm{~kg}$ and a BMI up to $27.7 \mathrm{~kg} / \mathrm{m}^{2}$. Moreover, some recent data show that

Table 9 Dietary intake of healthy women split into two groups based on of the Index of Fat Mass (IFM)

\begin{tabular}{lccc}
\hline & $\begin{array}{c}\text { Group C } \\
\text { Low fat mass } \\
\text { IFM }\end{array}$ & $\begin{array}{c}\text { Group D } \\
\text { High fat mass }\end{array}$ & p (*) \\
& N. $\mathbf{3 9}$ & IFM $>\mathbf{3 . 2 8}$ & \\
& $1530 \pm 650$ & $1410 \pm 580$ & 0.371 \\
\hline Water, ml & $11.30 \pm 16.60$ & $6.10 \pm 20.02$ & 0.217 \\
PRAL, mEq & $90 \pm 29$ & $81 \pm 20$ & 0.131 \\
Proteins, g/24 h & $278 \pm 92$ & $252 \pm 87$ & 0.204 \\
Carbohydrates, g/24 h & $93 \pm 32$ & $82 \pm 25$ & 0.112 \\
Lipids, mEq/24 h & $92 \pm 59$ & $82 \pm 25$ & 0.112 \\
Sodium, mEq/24 h & $71 \pm 23$ & $68 \pm 19$ & 0.521 \\
Potassium, mEq/24 h & $880 \pm 403$ & $719 \pm 349$ & 0.062 \\
Calcium, mg/24 h & $1199 \pm 440$ & $1056 \pm 308$ & 0.100 \\
Phosphorus, mg/24 h & $288 \pm 114$ & $268 \pm 112$ & 0.426 \\
Magnesium, mg/24 h & & &
\end{tabular}

Data were reported as mean \pm standard deviation.

${ }^{*} p$ value was calculated with independent Student's t-test. obesity does seem to determine a higher risk of nephrolithiasis in a children cohort, but surprisingly does not influence urine chemistries at all [22]. Finally, another recent report shows that in obese stone formers body composition does not influence stone chemistry until very high levels of BMI $\left(>40 \mathrm{~kg} / \mathrm{m}^{2}\right)$ are reached [29], thus indirectly supporting our finding that urine chemistry is poorly influenced by fat mass. In fact, it is remarkable to point out that in our research there was an average difference in body weight of about $13 \mathrm{~kg}$ between group C (low fat mass) and group D (high fat mass) (Table 7).

The relationship between lean mass and urine composition has been indeed poorly investigated in literature. However, our findings partially match with those by Lemann jr et al., who demonstrated that oxalate and calcium excretion in males is directly related to creatinine excretion, an index of lean mass composition, in a cohort of healthy subjects [8]. Thus, the increase of lean mass might cause a rise in the risk for calcium nephrolithiasis.

We may speculate that a high lean mass leads to higher protein catabolism, thus influencing the differences in urine composition we found in our research. We must also point out that subjects in group $\mathrm{B}$, the ones with a high lean mass, had also a higher prevalence of physical exercise, although not statistically significant. It is plausible that physical exercise may influence a more active muscular metabolism, thus causing a higher excretion of metabolites such as oxalate, phosphate and citrate.

The analysis of bone mineral density in our subjects confirmed the assumption, already well established in literature [18], that the higher is the body mass, the better is the quality of the bone, particularly in the spine (Table 7). The women with high IFM had a significantly higher bone mineral density in lumbar vertebrae, pelvis and femur. This group also shows a poor percentage of subjects regularly performing physical activity (26\% vs $54 \%)$. This tallies with published data showing that in premenopausal sedentary women bone mineral density correlates with fat mass [30]. However, we have to consider that in our model total body weigh increase when fat mass rise suggesting a non-linear dose-response relationship of fat mass on BMD as previous suggested [17]. On the other hand, the group with high lean mass shows better mineral density in upper and lower limbs and ribs. This group also includes subjects taller than the ones with low lean mass. It has already been demonstrated that height correlates with lean mass and mineral density of extra-axial bones [30,31]. We can also suppose that a better bone mineral density in limbs and ribs is, at least partially, due to physical exercise with a subsequent increase in muscle mass and mechanic anabolic stimulus on the bone $[32,33]$. 
We are aware of some limits that are implied in our study. First, the number of subjects studied is rather low. Secondly, the groups were split on the basis of mathematical indexes built to highlight lean mass and fat mass and not on the basis of direct measures. Moreover, we did not carry out an analysis distinguishing pre-menopausal and post-menopausal women. Finally, the analysis of a threeday dietary diary may not exhaustively capture the real dietary habits of a subject; nevertheless the diaries were interpreted by a dietitian during a meeting and the results do not change even after correction for body weight.

\section{Conclusions}

This paper suggests that in healthy women with a similar dietary intake, fat mass does not seem to influence the urinary excretion of lithogenic risk factors, which on the other hand seems to be much more dependent on the level of lean mass. Moreover, bone mineral density seems to be influenced by fat mass, while lean mass might play a positive role particularly on the extra-axial skeleton, as a possible result of the muscular activity. However, the field of interactions between body composition and mineral metabolism is far from being fully understood. Further research on larger cohorts both of healthy subjects and kidney stone formers or people with osteoporosis will clarify the specific role of lean mass and fat mass.

\section{Abbreviations}

BMD: Bone mineral density; DEXA: Dual Energy X-ray Absorptiometry; ILM: Index of lean mass; IFM: Index of fat mass; BMI: Body mass index; BW: Body weight; LM: Lean mass; FM: Fat mass; PRAL: Potential renal acid load.

\section{Competing interests}

The authors declare they have not competing interests.

\section{Authors' contributions}

AN, ATi, AG carried out study design, data interpretation and manuscript preparation; FA, ED, ATe: participants enrollment and clinical assessment; SP and GL: laboratory tests and supervision; MP: DEXA execution and interpretation; GF and PB: statistical analysis; LB and LS: critical revision; TM: critical revision, organization and supervision. All authors read and approved the final manuscript.

\section{Acknowledgements}

This work was financed by grants from Italian Ministry of University and Research as part of a larger project about the prevention of kidney stones (PRIN 2005063822).

\section{Author details \\ ${ }^{1}$ Department of Clinical and Experimental Medicine, University of Parma, Via A. Gramsci 14, Parma 43126, Italy. ${ }^{2}$ Department of Mathematics, Uppsala University, Uppsala, Sweden. ${ }^{3}$ Laboratory of Clinical Chemistry and Haematology, Department of Pathology and Laboratory Medicine, Parma University Hospital, Parma, Italy. ${ }^{4}$ Department of Health Sciences, Università degli Studi di Milano, Milan, Italy.}

Received: 21 June 2013 Accepted: 1 October 2013 Published: 7 October 2013

\section{References}

1. Curhan GC, Willett WC, Rimm EB, et al: Body size and risk of kidney stones. J Am Soc Nephrol 1998, 9:1645.
2. Taylor EN, Stampfer MJ, Curhan GC: Obesity, weight gain, and the risk of kidney stones. JAMA 2005, 293:455.

3. Daudon $M$, Lacour $B$, Jungers $P$ : Influence of body size on urinary stone composition in men and women. Urol Res 2006, 34:193.

4. Lee SC, Kim YJ, Kim TH, et al: Impact of obesity in patients with urolithiasis and its prognostic usefulness in stone recurrence. J Urol 2008, 179:570.

5. Ekeruo WO, Tan $\mathrm{YH}$, Young MD, et al: Metabolic risk factors and the impact of medical therapy on the management of nephrolithiasis in obese patients. J Urol 2004, 172:159.

6. Curhan GC, Willett WC, Speizer FE, et al: Twenty-four-hour urine chemistries and the risk of kidney stones among women and men. Kidney Int 2001, 59:2290.

7. Remer T, Berkemeyer S, Rylander R, et al: Muscularity and adiposity in addition to net acid excretion as predictors of 24-hour urinary $\mathrm{pH}$ in young adults and elderly. Eur J Clin Nutr 2007, 61:605.

8. Lemann J jr, Pleuss JA, Worcester EM, et al: Urinary oxalate excretion increases with body size and decreases with increasing dietary calcium intake among healthy adults. Kidney Int 1996, 49:200.

9. Taylor EN, Curhan GC: Body size and 24-hour urine composition. Am J Kid Dis 2006, 48:905.

10. Siener R, Glatz $S$, Nicolay $C$, et al: The role of overweight and obesity in calcium oxalate stone formation. Obes Res 2004, 12:106.

11. Duffey BG, Pedro RN, Kriedberg C, et al: Lithogenic risk factors in the morbidly obese population. J Urol 2008, 179:1401.

12. Eisner BH, Eisenberg ML, Stoller ML: Relationship between body mass index and quantitative 24-hour urine chemistries in patients with nephrolithiasis. J Urol 2010, 75:1289.

13. Negri AL, Spivacow FR, Del Valle EE, et al: Role of overweight and obesity on the urinary excretion of promoters and inhibitors of stone formation in stone formers. Urol Res 2008, 36:303.

14. Sarica K, Altay B, Erturhan S: Effect of being overweight on stone-forming risk factors. Urology 2008, 71:771

15. Meschi T, Nouvenne A, Ticinesi A, et al: Dietary habits in women with recurrent idiopathic calcium nephrolithiasis. J Trans/ Med 2012, 10:63.

16. Meschi T, Nouvenne A, Borghi L: Lifestyle recommendations to reduce the risk of kidney stones. Urol Clin North Am 2011, 3:313-20.

17. Gjesdal CG, Halse Jl, Eide GE, Brun JG, Tell GS: Impact of lean mass and fat mass on bone mineral density: the Hordaland Health Study. Maturitas 2008, 59:191-200.

18. Reid IR: Relationships between fat and bone. Osteoporos Int 2008, 19:595.

19. Elia M: Obesity in the elderly. Obes Res 2001, 9:244S.

20. Haroun D, Wells JCK, Williams JE, et al: Composition of the fat-free mass in obese and nonobese children: matched case-control analyses. Int J Obes 2005, 29:29.

21. Frassetto L, Morris RC, Sebasian A: Long-term persistence of the urine calcium-lowering effect of potassium bicarbonate in postmenopausal women. J Clin Endocrinol Metab 2005, 90:831.

22. Ayoob R, Wang W, Schwarderer A: Body fat composition and occurrence of kidney stones in hypercalciuric children. Pediatr Nephrol 2011, 26:2173.

23. Schutz Y, Kyle UUG, Pichard C: Fat-free mass index and fat mass index percentiles in Caucasians aged 18-98 y. Int J Obes 2002, 26:953-960.

24. Hochberg Y: A sharper Bonferroni procedure for multiple tests of significance. Biometrika 1988, 75:800-802.

25. Remer T, Manz F: Potential renal acid load of foods and its influence on urine pH. J Am Diet Assoc 1995, 95:791-797.

26. Leenders NYJM, Sherman WM, Nagaraja HN, Kien CL: Evaluation of methods to assess physical activity in free-living conditions. Med SC Sports Exerc 2001, 33:1233.

27. Abate N, Chandalia M, Cabo-Chan AV, et al: The metabolic syndrome and uric acid nephrolithiasis: novel features of renal manifestation of insulin resistance. Kid Int 2004, 65:386.

28. Sakhaee K, Capolongo G, Maalouf NM, et al: Metabolic syndrome and the risk of calcium stones. Nephrol Dial Transplant 2012, 27:3201.

29. Kadlec AO, Greco K, Fridirici ZC, et al: Metabolic syndrome and urinary stone composition: what factors matter most? J Urol 2012, 80:805.

30. Reid IR, Legge M, Stapleton JP, et al: Regular exercise dissociates fat mass and bone density in premenopausal women. J Clin Endocrinol Metab 1995, 80:1764

31. Makovey J, Naganathan V, Sambrook P: Gender differences in relationships between body composition components, their distribution 
and bone mineral density: a cross-sectional opposite sex twin study. Osteoporos Int 2005, 16:1495.

32. Ozcivici $E$, Luu YK, Adler B, et al: Mechanical signals as anabolic agents in bone. Nat Rev Rheumatol 2010, 6:50.

33. Ozcivici E, Luu YK, Rubin CT, et al: Low-level vibrations retain bone marrow's osteogenic potential and augment recovery of trabecular bone during reambulation. PLoS One 2010, 5:e11178.

doi:10.1186/1479-5876-11-248

Cite this article as: Nouvenne et al.: Influence of lean and fat mass on

bone mineral density and on urinary stone risk factors in healthy women. Journal of Translational Medicine 2013 11:248.

\section{Submit your next manuscript to BioMed Central and take full advantage of:}

- Convenient online submission

- Thorough peer review

- No space constraints or color figure charges

- Immediate publication on acceptance

- Inclusion in PubMed, CAS, Scopus and Google Scholar

- Research which is freely available for redistribution 